\title{
LC determination and stability assessment of macrolide antibiotics azithromycin and spiramycin in bulk and tablet samples
}

\author{
A. Mahmoudi* \\ Laboratory of Research on Bioactive Products and Biomass Valorization (LRPBVB), \\ Ecole Normale Supérieure-Kouba, P.O. Box 92, Kouba, 16050, Algiers, Algeria \\ *E-mail address:mahmoudi_a2003@yahoo.fr
}

Keywords: Azithromycin, spiramycin, tablet dosage forms, stability study, HPLC-UV

\begin{abstract}
Development and validation of rapid HPLC method for quantifying macrolide antibiotics azithromycin (AZI) and spiramycin (SPI) in bulk and tablet samples is described. Determination was performed on a reversed phase $\mathrm{C}_{18}$ ODB column $(250 \times 4.6 \mathrm{~nm}$ I.D) at ambient temperature, and employing a UV-detection set at $210 \mathrm{~nm}$. The mobile phase consists of acetonitrile -2-methyl-2-propanol-hydrogenphosphate buffer, $\mathrm{pH} 6.2$, with $1.8 \%$ triethylamine $32: 8$ : up to $100, \mathrm{v} / \mathrm{v} / \mathrm{v})$, delivered at a flow-rate of $1.1 \mathrm{~mL} \mathrm{~min}^{-1}$. The assay is linear in concentration ranges of: $0.004-4.8$ and $0.0003-1.2 \mathrm{mg} \mathrm{mL}^{-1}$ for azithromycin and spiramycin, respectively, with detection limit of $0.02 \%$ for SPI and $0.03 \%$ for AZI. Recovery experiments revealed recovery of $98.51-$ $100.82 \%$. The applicability of this method in stability assessment studies is evaluated.
\end{abstract}

\section{INTRODUCTION}

Macrolide antibiotics are an important class that are used to treat respiratory tract, skin and skin-structure, sexually transmitted, and various other infections. They exert their antimicrobial activity by inhibiting ribosomal protein biosynthesis. Following the isolation of erythromycin and many other macrolides from fermentation broths of soil microbes, three generations of semisynthetic 14-, 15-, and 16-membered derivatives have been prepared and tested [1]. Of these compounds, azithromycin and spiramycin are used exclusively in medical and veterinary drugs, and that are commercially available as tablets.

Azithromycin is a novel semisynthetic macrolide or azalide similar to erythromycin but composed of a 15-membered lactone ring. As in erythromycin, cladinose and desosamine sugar residues are attachedat positions 3 and 5 (Fig. 1. A). Spiramycin consists predominantly of three closely related substances together with a number of other minor compounds [2]. The members of this series are composed of 16- membered lactone rings with two or three sugar substituents, mycaminose, forosamine and mycarose, together with various other substituent groups (Fig. 1. B).

Current official determination of antibiotics including macrolides is mainly carried out by microbiological assays [3]. The stability indicating method is a method that identifies the degradation products of analytes [4]. Since the microbiological assay is not stability-indicating [5], the presence of macrolides and any related degradation products in raw material or dosage forms cannot be established. In order to overcome these problems, analytical techniques are appropriate alternatives.

Numerous methods have been reported for analysis of AZI and SPI in in raw material, dosage forms and biological fluids, using voltammetry [6] NIR spectroscopy [7], spectrophotometry [8] and spectrofluorimetry [9]. Unfortunately, these methods were associated with some major disadvantages, such as lack of selectivity, time-consuming, tedious, and dedicated to sophisticate and expensive analytical instruments. Other reported methods are mostly based on chromatographic 

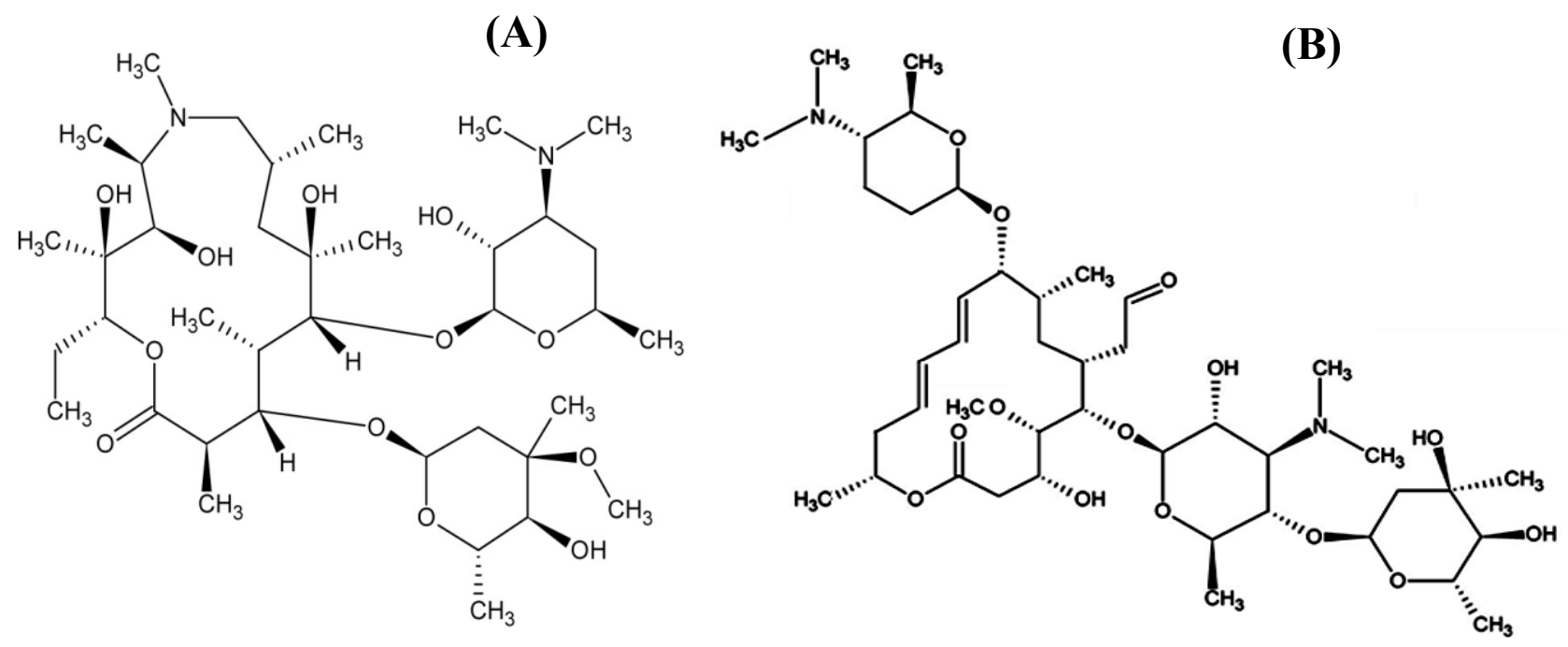

Fig. 1. Chemical structures of azithromycin (A) and spiramycin (B).

techniques. These include capillary zone electrophoresis [10] and high performance liquid chromatography (HPLC) [11-17] using UV detector [11-14], diode-array detector [15], electrochemical detector [16], fluorescence detector after precolumn derivatization [17,18] and liquid chromatography-mass spectrometry or LC-MS/MS [19-23].

Obviously, it would be a waste of LC with mass spectrometry if it was used for the routine quality control of AZI and SPI preparations. Meanwhile, pre-column derivatization is timeconsuming due to the complex steps involved. Moreover, electrochemical detectors are not widely available in many laboratories. However, the US Pharmacopeial method [24] describes specific conditions which are quite expensive and difficult to obtain. Also, the stability studies of dosage forms containing macrolides have received little attention, and few reports including AZI and SPI have been published. So development and validation of a simple, convenient and effective method for the analysis of these drugs is still required.

The objective of the present research was to develop and validate a simple, economic, precise and stability-indicating method to analyze AZI and SPI in bulk and tablet dosage forms using isocratic RP-HPLC method. In addition, stress testing of the drug was also conducted to support the suitability of this method to investigate the degradation of titled drugs.

\section{EXPERIMENTAL}

\subsection{Apparatus}

LC experiments were performed using a LC-10ATVP pump (shimadzu, Japan) equipped with an injector model Rheodyne (C.C, U.S.A) and a $25 \mu \mathrm{L}$ loop, a SPD -10AVP UV-vis detector (shimadzu, Japan) set at 210 and $232 \mathrm{~nm}$. The column was immersed in a water-bath, heated by a memert D-91126 thermostat (FRG, Germany). ODB column $(250 \times 4.6 \mathrm{~nm}$ I.D) was packed with silice uptisphere $5 \mu \mathrm{m}$ (interchim, France), the flow-rate was $1.1 \mathrm{~mL} \mathrm{~min}^{-1}$.

\subsection{Materials and reagents}

Spiramycin was purchased from Sigma (Steiheim, Germany) as pharmacopeial standards, and azithromycin working standard was kindly provided from SAIDAL-GROUPE (Saidal, Algeria), while pharmaceutical tablets containing these macrolide antibiotics were obtained commercially. Azithromycine BEKER ${ }^{\circledR}$ tablets (Laboratoires Beker, Algeria) was labeled to contain azithromycin as $500 \mathrm{mg} /$ tablet; Rovadal $^{\circledR}$ tablets (Saidal, Algeria): labelled to contain spiramycin as 1.5 MIU/tablet (equivalent of $1 \mathrm{IU}$ is $0.3 \mu \mathrm{g}$ ), respectively.

Dipotassium hydrogenphosphate, 2-methyl-2-propanol, methanol, triethylamine and absolute ethanol were of analytical-reagent grade from SIGMA-ALDRICH (Steiheim, Germany). Acetonitrile was of chemical grade from the same source. The following mobile phase was finally 
used: acetonitrile-2-methyl-2-propanol-0.030 $\mathrm{M}$ potassium phosphate buffer (pH 6.2) (32: 8: up to $100, \mathrm{v} / \mathrm{v} / \mathrm{v})$. The phosphate buffer solution was filtered through a Millipore GS $0.22 \mathrm{~mm}$ filter (Milford, MA, USA). Deionized or doubly distilled water was used throughout all experiments.

\subsection{Preparation of standard solutions}

Stock standard solutions of AZI were prepared by dissolving $400 \mathrm{mg}$ of this compound in 100 $\mathrm{mL}$ of $0.030 \mathrm{M}$ dipotassium hydrogen phosphate $(\mathrm{pH} 6.2)$-acetonitrile $(7: 3, \mathrm{v} / \mathrm{v})$, while a weighed quantity of $100 \mathrm{mg}$ of SPI was dissolved in $100 \mathrm{~mL}$ of water-acetonitrile $(7: 3, \mathrm{v} / \mathrm{v})$. The standard solutions were kept at $4^{\circ} \mathrm{C}$ in amber glass vessels. From each standard solution a series of dilution was prepared quantitatively in appropriate solvent to obtain standard solutions having concentration ranges of linearity. The solutions were prepared freshly every day and used as working standards (concentrations of AZI and SPI were 4.0 and $1.0 \mathrm{mg} \mathrm{mL}^{-1}$, respectively).

\subsection{Sample preparation}

\subsubsection{Azithromycine BEKER ${ }^{\circledR}$ tablets}

The sample preparation was done as follows based on a previous paper [9]. Ten tablets were weighed and finely powdered. A weighed portion equivalent to the weight of one tablet was transferred to a $100 \mathrm{~mL}$ volumetric flask, sonicated for $5 \mathrm{~min}$ with about $10 \mathrm{~mL}$ phosphate buffer(pH 6.2)-acetonitrile (7:3, v/v) then the solution was diluted to volume with the same solvent. The mixture was mixed well, allowed any insoluble matter to settle then filtered through a Millipore GS $0.22 \mathrm{~mm}$ filter. A measured volume of the filtrate was diluted quantitatively with the same solvent to yield a sample solution having a working concentration assumed to be $4.0 \mathrm{mg} \mathrm{mL}^{-1}$. This sample was evaluated in triplicate. This procedure was performed two times.

\subsubsection{Rovadal ${ }^{\circledR}$ tablets}

An amount equivalent to $450 \mathrm{mg}$ of spiramycin was transferred to $150 \mathrm{~mL}$ volumetric flask with $50 \mathrm{~mL}$ water-acetonitrile $(7: 3, \mathrm{v} / \mathrm{v})$ and shaken for $20 \mathrm{~min}$, followed by marking up to volume with the same solvent. After filtration, from this solution a series of dilution was prepared quantitatively in double distilled water to give a final concentration of $1.0 \mathrm{mg} \mathrm{mL}^{-1}$ of SPI. This sample was evaluated in triplicate. This procedure was performed two times.

\subsection{Validation of the method}

The linearity of an analytical method is its ability to elicit that test results are proportional to the concentration of analyte in samples within a given range. This was determined by means of calibration graph using increasing amounts of standard solutions $(0.004-4.8$ and $0.0003-1.2 \mathrm{mg}$ $\mathrm{mL}^{-1}$ for azithromycin and spiramycin, respectively). These standards were tested six times in agreement to the International Conference on Harmonization ( $\mathrm{ICH})$. Calibration curves were constructed and the proposed method was evaluated by its correlation coefficient and intercept value, calculated in the corresponding statistical study (ANOVA) $(\mathrm{p}<0.05)$.

The precision is a measure of the ability of the method to generate reproducible results. The precision of the assay was determined by repeatability (intra-day) and intermediate precision (interday) and reported as \%RSD. For this, several solutions were measured three times in a day and the same was repeated in next three days at 80,100,120\% levels. Accuracy indicates the deviation between the mean value found and the true value. Accuracy was determined by means of recovery experiments, by the addition of active drugs to samples. The accuracy was calculated from the test results as the percentage of the analyte recovered by the assay.

The limit of quantification for each antibiotic was defined as that concentration level where accuracy and precision were still better than $20 \%$. To determine the limit of detection on column, a dilute $\left(5.0 \mu \mathrm{g} \mathrm{mL}^{-1}\right)$ solution of the drugs in methanol-water $(50: 50, \mathrm{v} / \mathrm{v})$ was injected into the HPLC system. The limit of detection was then defined as the amount of antibiotic which caused a signal three times the noise $(\mathrm{S} / \mathrm{N}=3)$. The robustness of the method was assessed by altering the some experimental conditions such as, by changing the flow rate, amount of acetonitrile and the 
temperature of the column. Determine the concentration of the drug in tablets using the corresponding regression equation.

\subsection{Force degradation study}

\subsubsection{Preparation of stock solution}

Different aliquots of standard preparation and solutions of all excipients were used in all the force degradation studies. Stock solution of macrolides was prepared by dissolving $400 \mathrm{mg}$ of AZI and $50 \mathrm{mg}$ of SPI separately in a $100 \mathrm{~mL}$ of volumetric flasks containing $50 \mathrm{~mL}$ of mobile phase and the solutions were sonicated for 5 min and then volume was made up to the mark with mobile phase to get a concentrations of 4.0 and $0.5 \mathrm{mg} \mathrm{mL}^{-1}$ for AZI and SPI, respectively.

\subsubsection{Acid, acid, alkali and hydrogen peroxide induced degradation product}

To $25 \mathrm{~mL}$ of stock solution, $5 \mathrm{~mL}$ of $2 \mathrm{~N} \mathrm{HCl}, 5 \mathrm{ml}$ of $2 \mathrm{~N} \mathrm{NaOH}$ and $5 \mathrm{ml}$ of $3 \%(\mathrm{w} / \mathrm{v}) \mathrm{H}_{2} \mathrm{O}_{2}$ were added separately in volumetric flasks. These solutions were refluxed for $2 \mathrm{~h}$ at room temperature. The forced degradation in acidic, basic and oxidative media was performed in the dark in order to exclude the possible degradative effect of light. After the completion of the process, the solutions were neutralized and suspended in mobile phase, then analyzed by the procedure described above. acid, alkali and hydrogen peroxide

\subsubsection{Photochemical degradation product}

The photochemical stability of the drug was also studied by exposing the stock solution to natural light and UV lamp during $24 \mathrm{~h}$. Following the completion of the process, samples were prepared then analyzed as described in the previous section.

\subsubsection{Dry heat degradation products}

In order to examine thermal degradation processes, the commercial powder of drugs containing 400 and $50 \mathrm{mg}$ of AZI and SPI, respectively were stored at $70{ }^{\circ} \mathrm{C}$ for $2 \mathrm{~h}$ in oven. The resultant products were transferred to $100 \mathrm{ml}$ volumetric flask, dissolved in mobile phase and volume was made up to the mark. Further dilution was made to get a subjected concentration. An aliquot of $25 \mu \mathrm{L}$ was injected into the HPLC apparatus.

\subsection{Stability test of the assay preparation}

The stability of AZI and SPI in solution form was determined by HPLC analysis of three replicates of quality control samples $(25 \mu \mathrm{L}$ of theoretical concentration), stored in a refrigerator at $4^{\circ} \mathrm{C}$ for three consecutive weeks as well as at room temperature $\left(25^{\circ} \mathrm{C}\right)$ for $8 \mathrm{~h}$. stability study was computed by comparing the pertinent detector response from tested solutions after storage with that of freshly prepared.

In the case of the simultaneous study sample, several volumes of AZI and SPI working samples were added to $10 \mathrm{~mL}$ flask. After slightly mixing, the obtained homogenized mixture was filtered. Then, a $25 \mu \mathrm{L}$ of the filtrate solution was then injected into the HPLC system.

\section{RESULTS AND DISCUSSION}

\subsection{Optimization of chromatographic conditions}

The analytical method used in the stability study was based on a modification of the procedure previously used in our laboratory for the determination of macrolides. The modifications to the method included the use of $0.03 \mathrm{M}$ potassium phosphate buffer instead of that described at $0.025 \mathrm{M}$, since it allowed better separation between AZI and SPI.

Experiments to verify further the separation of macrolides were carried out at lower mobile phase $\mathrm{pH}$ (6.2 instead of 6.5). The temperature of the column was reduced from 30 to $25^{\circ} \mathrm{C}$, because at this temperature both macrolides are stable and although an increase in temperature had no significant effect on retention times, separation was carried out at room temperature for convenience. The composition of the organic modifier in the mobile phase was then investigated. Therefore, it became obvious that acetonitrile required another co-modifier to improve its 
selectivity. Other organic modifiers, such as methanol and 2-methyl-2-propanol, were studied. The effect of 2-methyl-2-propanol and acetonitrile in the mobile phase was studied in dependently. Based on the results obtained, it was concluded that a mixture of alcohols is necessary in order to obtain good separation between AZI and SPI.

A mobile phase containing acetonitrile- 2-methyl-2-propanol- $0.030 \mathrm{M}$ potassium phosphate buffer $\mathrm{pH} 6.2$ (32: 8: up to $100, \mathrm{v} / \mathrm{v} / \mathrm{v}$ ) was finally chosen and used isocratically to show the repeatability of the separation on reversed-phase ODB column. With a flow rate of $1.1 \mathrm{~mL} \mathrm{~min}^{-1}$ no back pressure problem was observed. Using these new LC conditions, SPI was eluted closely after the solvent peak, which made proper integration difficult. Therefore, $1.8 \%$ triethylamine was added, to improve the efficiency of separation. Nevertheless, drugs show absorption maxima at different wavelengths (210 $\mathrm{nm}$ for AZI and $232 \mathrm{~nm}$ for SPI).

\subsection{Analytical method validation}

The experiment was carried out according to the official specifications of Refs. [24-27]. The method was validated for the parameters like selectivity, linearity, sensitivity, precision, accuracy, and robustness.

\subsubsection{Specificity and selectivity}

The specificity of the analytical method was determined by comparing the results from an analysis of samples containing impurities, degradation products, or excipients with those obtained from pure standards. To ensure the absence of interfering response values, the selectivity of the method was evaluated by comparison of the chromatograms of drug standard and sample solution. The chromatographic parameters show a good correlation between the results of two determinations (e.g. for AZI: $\mathrm{y}=0.989 \mathrm{x}+0.056 ; \mathrm{n}=12 ; \mathrm{r}=0.98$ ). This interference study indicated no interfering peak around the studied retention times, and all endogenous substances were separated from principal peak; also baseline showed no any significant noise. In order to confirm this result, a given portion of placebo was prepared in mobile phase and injected into the chromatograph. Results indicate that excipients have no interference with both macrolides. Furthermore, the Student's $t$ values of AZI and SPI calculated for assay of the commercial lots and the recovery study, 1.84 and 1.57, respectively, are below tabulated values $\left(t_{n-1}, \alpha / 2\right.$ from tables $=2.571$, for five freedom degrees). These results showed that the proposed method can be considered specific.

\subsubsection{Linearity, limits of detection and quantification}

The calibration curve obtained by analysis $(n=7)$ of a series of analyte concentrations corresponding to $0.1,1,5,25,75,100$ and $120 \%$ of theoretical value $\left(4.0 \mathrm{mg} \mathrm{mL}^{-1}\right.$ for AZI and 1.0 $\mathrm{mg} \mathrm{mL}^{-1}$ for SPI) was subjected to linear regression analysis: $\mathrm{y}=503657.84 \mathrm{x}+5557.96$ for azithromycin and $\mathrm{y}=503657.84 \mathrm{x}+5557.96$ for spiramycin, where $\mathrm{y}$ is the peak-height and $\mathrm{x}$ the concentration $\left(\mathrm{mg} \mathrm{mL}^{-1}\right)$; correlation coefficients (r) were equal to 0.9995 and 0.9998 for AZT and SPI, respectively. To present suitability of this method, the sensitivity has been determined, since the limit of quantification was not realized according ICH guidelines. For an injection of $25 \mu \mathrm{L}$, the limit of quantitation (LOQ) (in $\%, \mathrm{~m} / \mathrm{m}$ ) with a signal-to-noise ratio of 10 was: $0.05 \%$ for SPI and $0.09 \%$ for AZI, and the limit of detection (LOD) with a signal-to-noise ratio of 3 was: $0.02 \%$ for SPI and $0.03 \%$ for AZI.

\subsubsection{Precision of method}

The precision of an analytical procedure expresses the closeness of agreement [27] (degree of scatter) between a series of measurements obtained from multiple sampling of the same homogeneous sample under the prescribed conditions. Precision of the method was demonstrated by repeatability (intra-day) and intermediate precision (inter-day) variation studies. The measurements of precision are expressed by relative standard deviations.

The intra-day precision was determined at three concentration levels for 1 day $(n=3)$, while the inter-day precision was determined for three separate days $(n=3 \times 3)$. Obtained results showed excellent precision with percent relative standard deviation ( $\%$ RSD) was less than $2.0 \%$ and $1.9 \%$ 
for AZI and SPI, respectively shown in table 1. This indicated that method was highly precise and suitable for the quantitation of drugs in stability studies.

Table 1. Intra- and inter-day precisions for the HPLC analysis of AZI and SPI.

\begin{tabular}{|c|c|c|c|c|c|c|}
\hline \multirow[t]{3}{*}{ Compound } & \multicolumn{3}{|c|}{ Intra-day $(\mathrm{n}=3)$} & \multicolumn{3}{|c|}{ Inter-day ( $\mathrm{n}=3 \times 3$ days) } \\
\hline & \multicolumn{3}{|c|}{$\%$ RSD } & \multicolumn{3}{|c|}{$\%$ RSD } \\
\hline & Low $^{\mathrm{a}}$ & Medium $^{\mathrm{b}}$ & $\operatorname{High}^{\mathrm{c}}$ & Low $^{a}$ & Medium $^{b}$ & $\mathrm{High}^{\mathrm{c}}$ \\
\hline Azithromycin & 1.1 & 1.5 & 1.4 & 1.3 & 1.7 & 1.9 \\
\hline Spiramycin & 1.2 & 1.3 & 1.7 & 1.4 & 1.5 & 1.8 \\
\hline
\end{tabular}

a,b,c The concentrations used were at the $80,100,120 \%$ levels.

\subsubsection{Accuracy and recovery studies}

The accuracy of an analytical procedure expresses the closeness of agreement between the value found and the value accepted as the conventional true value. The closeness of agreement observed is the resultant (total error) of the sum of the systematic and random errors, also the sum of the trueness and the precision [27].

Recovery studies were performed to judge the accuracy of the method. The studies were carried out by adding a known quantity of pure drug to the pre-analyzed formulation and the proposed method was followed. From the amount of drug found, the percent recovery was calculated. Recovery study was carried out at three levels $80 \%, 100 \%$ and $120 \%$ for the formulation concentration (Table 2).

The mean percentage recoveries value which was greater than $100 \%$, indicated the absence of interference of the excipients present in the tablet formulation, and confirmed the accuracy of the proposed method.

Table 2. Experimental values (\%) obtained in the recovery study for AZI and SPI in samples, by the developed HPLC.

\begin{tabular}{llll}
\hline Level of Addition (\%) & Addition of pure drug $\left(\boldsymbol{\mu g} \mathbf{~ m L}^{-\mathbf{1}}\right)$ & $\mathbf{\%}$ Recovery of pure drug & Recovery (\%) \pm SD \\
\hline Azithromycin & & & \\
80 & 400 & 100.36 & \\
100 & 500 & 100.52 & $100.35 \pm 0.17$ \\
120 & 600 & 100.18 & \\
Spiramycin & & & \\
80 & 360 & 100.82 & $100.48 \pm 0.31$ \\
100 & 450 & 100.44 & \\
120 & 540 & 100.20 & \\
\hline
\end{tabular}

\subsubsection{Robustness and ruggedness}

Robustness is an important aspect of method validation. One evaluates the influence of small changes in the operating conditions (variables) of the analytical procedure on measured or calculated responses. It was performed by small but deliberate variation in the chromatographic conditions and was found to be unaffected by small variations like $\pm 1.5 \%$ in volume of mobile phase composition, $\pm 0.1 \mathrm{~mL} \mathrm{~min}^{-1}$ in flow rate of mobile phase and $\pm 2{ }^{\circ} \mathrm{C}$ change in column temperature, and RSD did not exceed 5\%. It was observed that there were no marked changes in the chromatograms, which demonstrated that the proposed method was robust.

The ruggedness study of the method was determined by carrying out the analysis of studied macrolides using the same operational conditions by different analyst in different laboratories and different elapsed time. Results obtained due to lab-to-lab and day-to-day variations were found reproducible as RSD did not exceed 3.5\%. Over all analysis experiments, no change in the column 
efficiency and back pressure was also observed over the entire study time, thus proving its suitability.

\subsection{Stability of drug in the solutions}

Stock solutions of AZI and SPI were stable for $8 \mathrm{~h}$ and 21 days when stored at $4^{\circ} \mathrm{C}$ in refrigerator and at room temperature $\left(25^{\circ} \mathrm{C}\right)$, respectively. Whereas, the concentrations of solutions were found to be $>98 \%$ of the initial values, indicated that there are no significant changes in drug quantity, with a RSD remained to be less than $2.5 \%(n=5)$.

\subsection{Stress degradation study}

The capability of stability-indicating assay was examined through stress testing. Standards, samples and placebo were subjected to the following conditions: acidic, basic and oxidative degradation using $2 \mathrm{~N} \mathrm{HCl}, 2 \mathrm{~N} \mathrm{NaOH}$ and $\mathrm{H}_{2} \mathrm{O}_{2}(3 \%)$, respectively. In addition, thermal and photo degradation using natural light and UV radiance were studied. In acidic, basic and oxidative degradation processes of AZI and SPI was performed for $2 \mathrm{~h}$ at $25^{\circ} \mathrm{C}$, and then the solutions were neutralized and diluted with mobile phase. Finally, a $25 \mu \mathrm{L}$ aliquot of each treated macrolide was injected into the HPLC system for subsequent analysis. Fig. $2 \mathrm{~A}-\mathrm{E}$ and Fig. $3 \mathrm{~A}-\mathrm{E}$ show the chromatograms of AZI and SPI, respectively in their stress conditions, which indicate that all the degradation products formed were detected. Fig. 2 A and Fig. 3 A shows the chromatograms of the Standards before exposure to stress conditions.

In order to investigate the thermal degradation of sample, a small portion of commercial powder samples of both macrolides were kept at $70{ }^{\circ} \mathrm{C}$ for $2 \mathrm{~h}$. Photo degradation was performed as well for the same samples by exposing them to daylight and UV lamp radiation for $24 \mathrm{~h}$ at $25^{\circ} \mathrm{C}$. The results showed that the degradation rate of these products were negligible in initial hours (Fig. 2 and 3). The placebo was submitted to the same degradation conditions in order to demonstrate no interference. All degradation studies showed that the degradation products were well separated from pure macrolide peak, confirming the stability indicating capability of the method.

Macrolide antibiotics are characterized by the presence of a large macrocyclic lactone ring containing a series of conjugated double bonds and one or more sugar residues. Solutions of AZI and SPI in a methanol-water mixture at $\mathrm{pH}$ 7-9 have been described to be stable at room temperature for several hours $[1,2]$. This was confirmed by the fact that the reference solutions used did not show any sign of decomposition over the period of use in a series of analysis. However, in acidic, basic and oxidative stress conditions peaks corresponding to AZI and SPI were decreased, indicated degradation products could be expected to be formed in significant amounts during stress processes, and new peaks were observed (Fig. 2 and 3).

This effect can be explained by the fact that SPI forms neospiramycin products when mycarose moiety was interrupted from the lactone ring. Similar possible explication that, AZI can be formed inactive product also by the interruption of cladinose sugar [1,2], which is attached via a $\beta$ glycosidic linkage to the $\mathrm{C}-3$ position of its lactone ring (Fig. 1). 


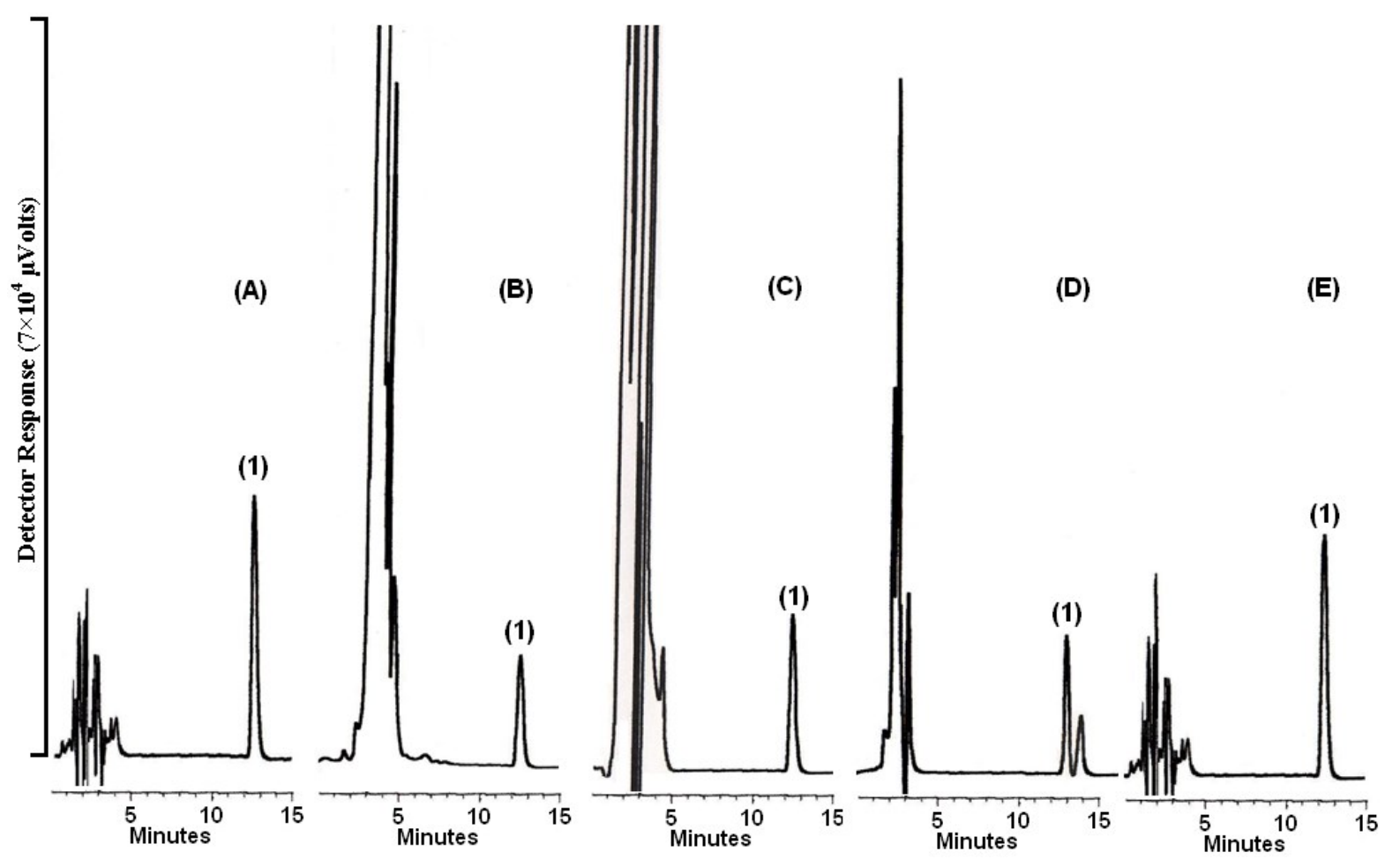

Fig. 2. Chromatograms corresponding to azithromycin as standard (A) and as raw material treated with acid (B), alkali (C) and hydrogen peroxide (D), and exposed to natural light and UV lamp (E). Mobile phase: Acetonitrile-2-methyl-2-propanol-0.030 M potassium phosphate buffer ( $\mathrm{pH}$ 6.2) (32: 8: up to 100, $\mathrm{v} / \mathrm{v} / \mathrm{v})$; stationary phase: $\mathrm{ODB} \mathrm{RP}_{18} 5 \mu \mathrm{m}\left(250 \times 4.6 \mathrm{~mm}\right.$ I.D.); flow-rate: $1.1 \mathrm{ml} / \mathrm{min}$; temperature: $25{ }^{\circ} \mathrm{C}$; detection: $\mathrm{UV}$ at $210 \mathrm{~nm}$. Retention time of azithromycin (1) was $12.35 \mathrm{~min}$.
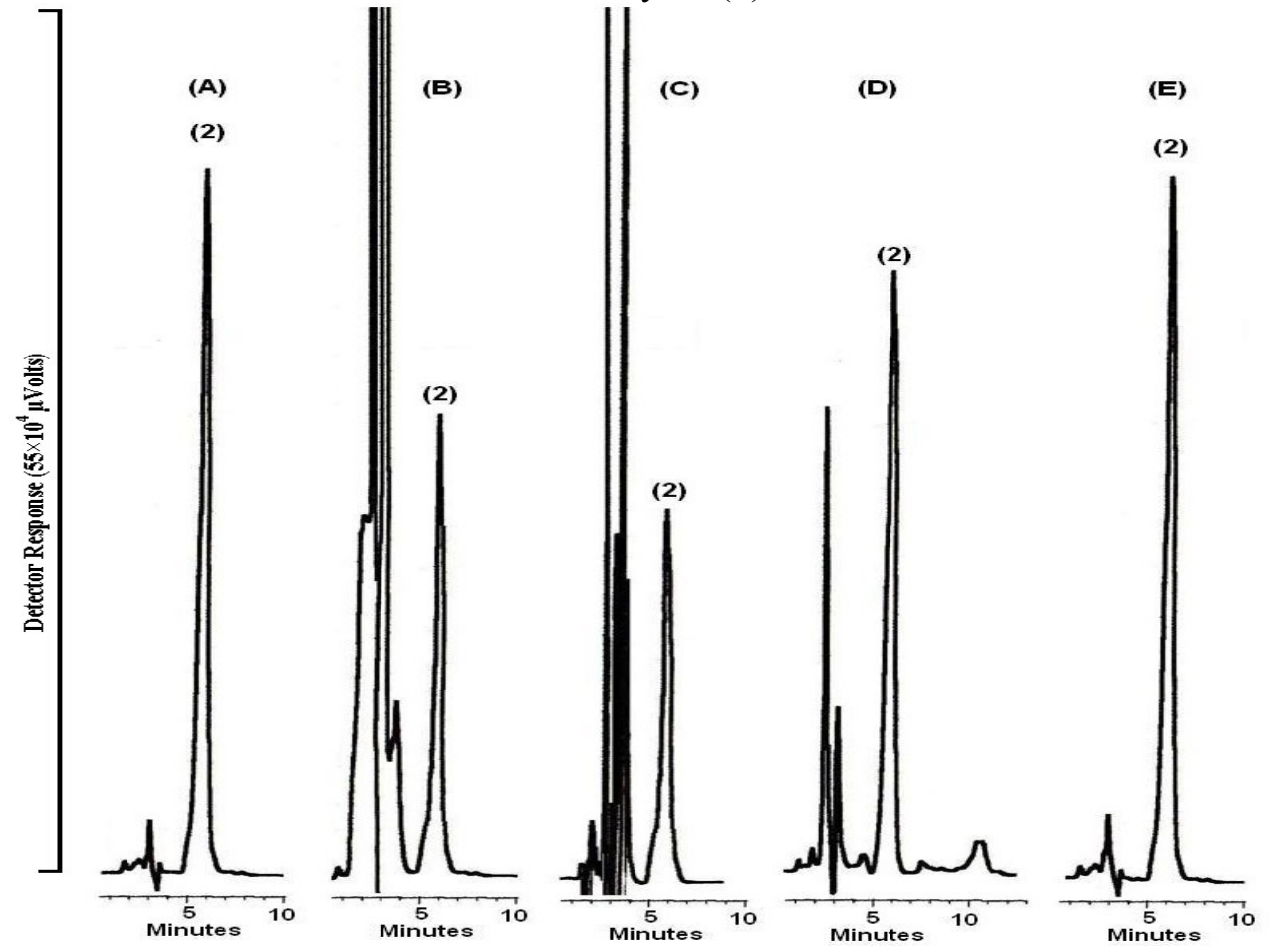

Fig. 3. Chromatograms corresponding to spiramycin as standard (A) and as raw material treated with acid (B), alkali (C) and hydrogen peroxide (D), and exposed to natural light and UV lamp (E). For the chromatographic conditions see Fig. 2. Retention time of spiramycin (2) was 5.83 min.

\subsection{Analytical applications}

This method was applied to assay certain available commercial products tablets by analyzing Azithromycine BEKER ${ }^{\circledR}$ and Rovadal ${ }^{\circledR}$ tablets as described in Section 2. The assay results of AZI and SPI for these dosage forms were comparable with the label value claimed. The results of drug 
assays are summarized in Table 3. Using the proposed method, a good recovery was obtained without any interference from coexisting substances. Further, as shown in Fig. 4 for simultaneous determination of both macrolides, no endogenous materials interference was observed at the retention times of AZI and SPI. Therefore, these findings indicate that the developed method can be proposed for determination of titled drugs in biological matrices and multi screened for residual amounts of these substances in veterinary practices, since the analyzes were confirmed with spiked samples of some biological matrices.

Table 3. Assay of Azithromycin and Spiramycin in tablet dosage forms

\begin{tabular}{cccccc}
\hline SN & Brand $^{\mathrm{a}}$ & Label claim & $\begin{array}{c}\text { Amount found } \\
(\mathrm{mg})\end{array}$ & $\begin{array}{c}\text { Recovery } \\
(\%)\end{array}$ & $\begin{array}{c}\text { RSD } \\
(\%)\end{array}$ \\
\hline 1 & Azithromycine BEKER $^{(B}$, & Azithromycin, 500mg/tablets & $492.55 \pm 9.01$ & 98.51 & 1.83 \\
tablets & Rovadal $^{\circledR}$, tablets & Spiramycin $^{\mathrm{c}}, 450 \mathrm{mg} /$ tablets & $445.89 \pm 7.11$ & 99.08 & 1.59 \\
\hline
\end{tabular}

${ }^{a}$ Brand (1) Laboratoires BEKER, Algiers, Algeria, Lot No.037314, Manufactured Sep. 2014; (2) Saidal, Algiers, Algeria, Lot No. 0029, Manufactured Mar. 2014.

${ }^{\mathrm{b}}$ Average of three experiments $\pm \mathrm{SD}$.

${ }^{\mathrm{c}} \mathrm{Label}$ claim is $1.5 \mathrm{MIU} /$ tablet (equivalent of $1.5 \mathrm{MIU}$ is $450 \mathrm{mg}$ ).

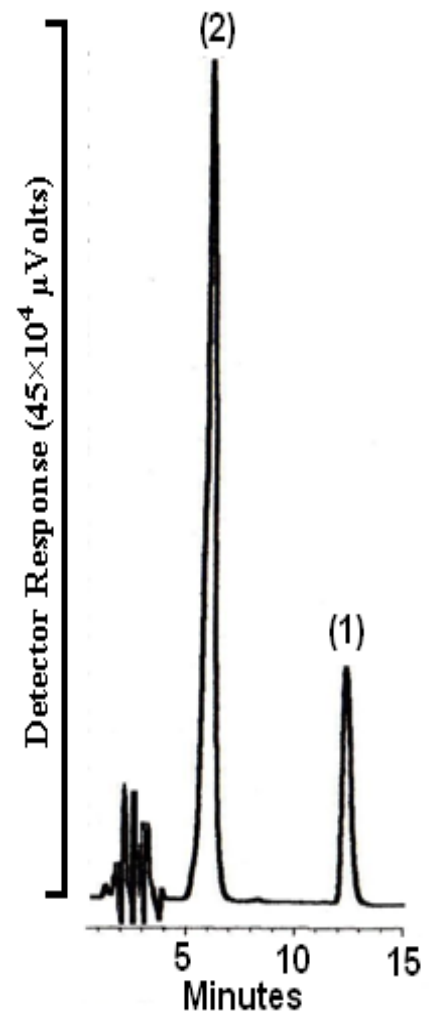

Fig. 4. Reprehensive chromatogram corresponding to simultaneous determination of azithromycin (1) and spiramycin (2). For the chromatographic conditions see Fig. 2. Retention times were 5.89 and 12.47 min of spiramycin and azithromycin, respectively.

\section{CONCLUSION}

In conclusion, a new, affordable, cost-effective and convenient LC method has been described for the accurate determination of azithromycin and spiramycin in bulk and tablet dosage forms. Hence, it is sensitive, specific, precise, rapid and simple offering distinct advantages over the reported microbiological assays which are relatively imprecise, time-consuming and tedious to perform. From the economical point of view, all the analytical reagents are inexpensive, have good shelf life, and are available in any analytical laboratory and it does not need expensive sophisticated apparatus. Furthermore, this method has demonstrated to be suitable for its use in quality control and stability assessment assays of AZI and SPI. 


\section{Acknowledgments}

Authors acknowledge the financial support from the project CNEPRU (No. E1611/03/04) from the Ministry of Higher Education and Scientific Research of the Algerian Republic. Authors are also thankful to SAIDAL-GROUPE of Algeria for providing gift standard of Azithromycin.

\section{References}

[1] J. Elks, C.R. Ganellin (Eds.), Dictionary of Drugs, Chapman and Hall, London, 1991.

[2] S. Omura (Ed.), Macrolide Antibiotics: Chemistry, Biology and Practice, Academic Press, Orlando, FL, 1984.

[3] A. Mahmoudi, R.E.-A. Fourar, M.S. Boukhechem, S. Zarkout, Int. J. Pharm. 491 (2015) 285291.

[4] L.C. Vaucher, C.S. Paim, A.D. Lange, E.E.S. Schapoval, Int. J. Pharm. 366 (2009) 82-87.

[5] C. Stubbs, I. Kanfer, Int. J. Pharm. 63 (1990) 113-119.

[6] O. Farghaly, N. Mohamed, Talanta 62 (2004) 531-538.

[7] C. Boyer, K. Gaudin, T. Kauss, A. Gaubert, A. Boudis, J. Verschelden, M. Franc, J. Roussille, J. Boucher, P. Olliaro, N.J. White, P. Millet, J-P. Dubost, J. Pharm. Biomed. Anal. 67- 68 (2012) 1015.

[8] S. Ashour, R. Bayram, Spectrochim Acta Part A: Mol. Biomol. Spectrosc. 99 (2012) 74-80.

[9] P.Y. Khashaba, J. Pharm. Biomed. Anal. 27 (2002) 923-932.

[10] A.P. Kumar, J.H. Park, J. Chromatogr. A. 1218 (2011) 1314-1317.

[11] H.K. Chepkwony, A. Vermaelen, E. Roets, J. Hoogmartens. Chromatographia 54 (2001) 5156.

[12] N. Furusawa, Talanta. 49 (1999) 461-465.

[13] Z.Y. Yang, L.Wang, X. Tang, J. Pharm. Biomed. Anal. 49 (2009) 811-815.

[14] F.N. Kamau, H.K. Chepkwony, J.K. Ngugi, E. Roets, J. Hoogmartens, J. Chromatogr. Sci. 40 (2002) 529-533.

[15] C. Leal, R. Codony, R. Compañó, M. Granados, M. D. Prat, J. Chromatogr. A. 910 (2001) 285 -290 .

[16] M.J. González de la Huebra, U. Vincent, C. von Holst, J. Pharm. Biomed. Anal. 43 (2007) $1628-1637$.

[17] E. Wilms, H. Trumpie, W. Veenendaal, D. Touwa, J. Chromatogr. B. 814 (2005) 37-42.

[18] G. Bahrami, S. Mirzae, A. Kiani, J. Chromatogr. B. 820 (2005) 277-281.

[19] M.J. González de la Huebra, U. Vincent, G. Bordin, A.R. Rodríguez, Anal. Chim. Acta. 503 (2004) 247-256.

[20] M. Horie, H. Takegami, K. Toya, H. Nakazawa, Anal. Chim. Acta. 492 (2003) 187-197.

[21] R.V.S. Nirogi, V.N. Kandikere, M. Shukla, K. Mudigonda, S. Maurya, R. Boosi, A. Yerramilli, Anal. Chim. Acta. 553 (2005) 1-8.

[22] Y. Shen, C. Yin, M. Su, J. Tu, J. Pharm. Biomed. Anal. 52 (2010) 99-104.

[23] R.V. Nirogi, V.N. Kandikere, M. Shukla, K. Mudigonda, S. Maurya, R. Boosi, A. Yerramilli, Anal. Chim. Acta 553 (2005) 1-8.

[24] United States Pharmacopoeia 32ed, United States Pharmacopeial Convention, Rockville, MD, 2009, pp. 2292.

[25] British Pharmacopoeia, fifth ed., Her Majesty's Stationery Office Ltd., London, 2011.

[26] International Conference on Harmonization (ICH) of Technical Requirements for registration of Pharmaceuticals for Human Use Topic Q2 (R1): Validation of Analytical Procedures: Text and Methodology, Geneva, 2005.

[27] P. Hubert, J.J. Ngyen-Huu, B. Boulanger, E. Chapuzet, P. Chiap, N. Cohen, P.A. Compagnon, W. Dewe, M. Feinberg, M. Lallier, M. Laurentie, N. Mercier, G. Muzard, C. Nivet, L. Valat, Validation des procédures analytiques quantitatives: Harmonisation des démarches, STP. Pharma Pratiques. 13 (2003) 101-138. 